\title{
Detecting declines of apex carnivores and evaluating their causes: An example with Zambian lions
}

\author{
Elias Rosenblatt ${ }^{\mathrm{a}, \mathrm{b}, *}$, Matthew S. Becker ${ }^{\mathrm{a}, \mathrm{b}}$, Scott Creel ${ }^{\mathrm{a}, \mathrm{b}}$, Egil Droge ${ }^{\mathrm{a}, \mathrm{b}}$, Thandiwe Mweetwa ${ }^{\mathrm{a}, \mathrm{c}}$, \\ Paul A. Schuette ${ }^{\mathrm{a}, \mathrm{b}}$, Fred Watson ${ }^{\mathrm{a}, \mathrm{d}}$, Johnathan Merkle ${ }^{\mathrm{a}}$, Henry Mwape ${ }^{\mathrm{a}}$
}

a Zambian Carnivore Programme, Mfuwe, Eastern Province, Zambia

${ }^{\mathrm{b}}$ Department of Ecology, Montana State University, Bozeman, MT 59717, USA

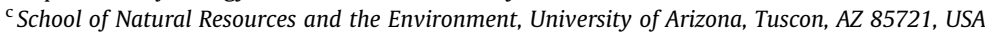

${ }^{\mathrm{d}}$ Division of Science and Environmental Policy, California State University Monterey Bay, CA 93955, USA

\begin{abstract}
A B S T R A C T
Large carnivores are in rapid global decline, with a broad array of consequences for the ecosystems they inhabit. To efficiently detect and address these declines requires unbiased and precise demographic data. Unfortunately, the characteristics that make large carnivores extinction-prone also pose serious challenges to obtaining these data. Rapid survey methods exist, but provide only relative measures of abundance, cannot detect declines before they become large, and provide little or no information about the causes of decline. African lions (Panthera leo) are declining throughout their range, making accurate monitoring of remaining populations urgent. We provide statistically rigorous estimates of population size, trends, survival rate and age-sex structure from Zambia's South Luangwa lion population from 2008 to 2012, just prior to cessation of hunting in 2013. Mark-recapture models fit to data from intensive monitoring of 210 individual lions in 18 prides and 14 male coalitions indicated a declining population, low recruitment, low sub-adult and adult male survival, depletion of adult males, and a senescing adult female population. Trophy hunting was the leading cause of death, with 46 males harvested. Based on these data we recommend continuing the hunting ban at least to 2016 to allow recovery, with substan-tially reduced quotas, age-limits, and effective trophy monitoring mandated thereafter should hunting resume. Similar data from intensive monitoring of key Zambian lion populations is required to evaluate effects of the hunting ban and provide management guidance. Effectively integrating intensive long-term monitoring and rapid survey methods should be a priority for future management and monitoring of carnivore species.
\end{abstract}

\section{Introduction}

The decline and extinction of large carnivores is one of the most pervasive human impacts on earth's ecosystems (Vitousek et al., 1997). While our understanding of carnivores' strong ecological effects continues to broaden (Estes et al., 2011), losses continue

Abbreviations: GMA, Game Management Area; IOA, indices of abundance; SLNP, South Luangwa National Park; ZAWA, Zambia Wildlife Authority; ZCP, Zambian carnivore programme.

* Corresponding author at: Department of Ecology, Montana State University, Bozeman, MT 59717, USA. Tel.: +1 4069945646.

E-mail addresses: elias@zambiacarnivores.org (E. Rosenblatt), matt@ zambiacarnivores.org (M.S. Becker), screel@montana.edu (S. Creel), egil@ zambiacarnivores.org (E. Droge), thandiwemweetwa@gmail.com (T. Mweetwa), paul@zambiacarnivores.org (P.A. Schuette), fwatson@csumb.edu (F. Watson), johnathan@zambiacarnivores.org (J. Merkle), hmwape@gmail.com (H. Mwape). to accelerate, and the majority of the world's large carnivores are currently threatened (Ripple et al., 2014). Large carnivores are typically low-density, wide-ranging, and elusive, with a propensity to conflict with humans; consequently, these species are very sensitive to human impacts even in protected areas, and often require large areas of relatively intact, contiguous tracts of habitat (Woodroffe and Ginsberg, 1998; Brashares et al., 2001; Woodroffe, 2000; Cardillo et al., 2004; Creel et al., 2013). Demographic data are of prime importance to inform and guide conservation efforts, but the characteristics that make large carnivores extinction-prone also hinder the collection of these data, particularly when populations are small and declining.

Population monitoring to describe dynamics typically yields data constrained by a trade-off between scale and precision. Intensive long-term studies of known individuals provide good precision (e.g. Packer et al., 1998; Peterson, 1999; Kelly and 
Durant, 2000), but are rare and relatively small scale due to their logistical difficulty, expense, and time-consuming nature (Durant et al., 2007). Consequently, a variety of rapid and economical survey methods have been developed to monitor large carnivore populations, including spoor counts (Van Dyke et al., 1986; Stander, 1998; Houser et al., 2009; Funston et al., 2010; Ferreira et al., 2013; Bauer et al., 2014; Midlane et al., 2014), audio lures (Ogutu and Dublin, 1998; Mills et al., 2001; Kiffner et al., 2008; Ferreira and Funston, 2010; Cozzi et al., 2013; Groom et al., 2014), camera trapping (Karanth and Nichols, 1998; Jackson et al., 2006; Balme et al., 2009; Karanth et al., 2011; Schuette et al., 2013), distance sampling (Durant et al., 2011), detection dogs (Smith et al., 2001), extrapolation from prey density (Karanth et al., 2004), and noninvasive genetic surveys (Kohn et al., 1999; Creel et al., 2003; Mondol et al., 2009; Creel and Rosenblatt, 2013). While these survey methods avoid some of the constraints inherent to intensive monitoring of known individuals, they often provide population estimates with confidence intervals so broad that they provide little guidance for management and conservation. Large (or unmeasured) variance in estimates of population size remains a substantial impediment to detecting carnivore declines, prioritizing areas for conservation, and assessing the effectiveness of management actions.

This problem is exemplified with Africa's largest carnivore, the lion (Panthera leo), which has declined throughout its range (Riggio et al., 2012) due to a combination of prey depletion and habitat loss, direct conflict and retaliatory killing, wire-snare poaching, and trophy hunting (Yamazaki, 1996; Ogada et al., 2003; Loveridge et al., 2007, 2010; Bauer et al., 2013; Packer et al., 2009, 2011; Becker et al., 2013a; Groom et al., 2014). The broad range of threats to lion population viability creates an urgent need for accurate data to describe population trends, identify underlying demographic changes and understand their causes. To assess lion density and monitor trends through time, indices of abundance (IOA; Conroy, 1996) such as spoor counts (Stander, 1998) have been widely adopted. While spoor counts can provide unbiased estimates of lion population size, the precision of these estimates must be carefully considered in assessments of lion and other large carnivore populations. As noted by Midlane (2014), the coefficient of variation has been calculated incorrectly in a sequence of studies that have used spoor counts to estimate lion density, in a manner that substantially over-estimates the method's precision (Stander, 1998; Funston et al., 2010; Ferreira et al., 2013; Bauer et al., 2014). Consequently, the ability of spoor counts to describe and evaluate trends in lion populations has been overstated. Another common lion monitoring strategy employs audio playback experiments (i.e. call-in surveys). These population estimates also have low precision and can be biased by variation in detection probability and methodology (Mills et al., 2001; Whitman, 2006; Kiffner et al., 2009; Brink et al., 2012; Cozzi et al., 2013). While IOA for lions and other carnivores are important conservation tools, precise estimates of population density, trends and vital rates and information about the probable causes of demographic patterns still depend primarily on intensive monitoring of known individuals.

Zambia is one of eight remaining African countries containing a lion stronghold (Riggio et al., 2012); however its lion populations are geographically and numerically limited by human encroachment, direct mortality due to wire-snare poaching by-catch, prey depletion due to poaching, trophy hunting, disease, and humanlion conflict (Yamazaki, 1996; ZAWA, 2009; Becker et al., 2013a, 2013b; Berentsen et al., 2013; Watson et al., 2013, 2014; Midlane et al., 2014; Lindsey et al., 2014). The relative importance of these factors, their trends through time, and the associated demographic impacts on lions are poorly understood. In response to growing concern over the status of Zambian lions and a lack of data on population size, distribution, and trends, the Zambia Wildlife Authority
(ZAWA) developed a National Conservation Strategy and Action Plan for the Lion, with the overall intent being "... to establish a science-based Conservation Strategy and Action Plan for the African Lion" (ZAWA, 2009). In January 2013, the government of Zambia enacted a ban on lion trophy hunting due to concern over potentially excessive quotas, alleged mismanagement, possible lion declines, and a lack of scientific data to assess the status of lions and other species (Mfula, 2013). To address these issues we use data from intensive monitoring of known individuals in a five-year (2008-2012) study of lions in South Luangwa National Park (SLNP) and the adjacent Lumimba and Lupande Game Management Areas (GMAs) to estimate age- and sex-specific survival rates and population size, density and growth rate using markrecapture models. We use these results to evaluate lion management policies in Zambia, and more broadly as an example of the importance of intensive monitoring for detecting, understanding and addressing large carnivore declines.

\section{Material and methods}

\subsection{Study area and data collection}

Our $2775 \mathrm{~km}^{2}$ intensive study area was located along the eastern boundary of SLNP and the adjoining Lupande and Lumimba GMAs, which collectively support a substantial portion of Zambia's largest lion population and its prime photo tourism and trophy hunting area (Fig. 1; ZAWA, 2010). While national parks are strictly protected, GMAs are IUCN Category VI areas that serve as buffer zones to national parks and allow human settlement and a variety of natural resource-based uses (Dudley, 2008; Chomba et al., 2011), including trophy hunting of male lions (Yamazaki, 1996; Becker et al., 2013b; see Section 4.3). Our study area thus encompassed two wildlife management regimes, with associated variations in human influence, available habitats, and potential prey.

The study area included a mosaic of edaphic grassland, deciduous riparian forest, miombo (Brachystegia spp) woodland, mopane (Colophospermum mopane) woodland and scrubland, dry deciduous forest, and undifferentiated woodland (Astle, 1988; Astle et al., 1969; White, 1983). The perennial Luangwa River forms most of the eastern border of the park, though lions and other wildlife move freely between SLNP and adjacent GMAs. The Luangwa valley experiences two distinct seasons: a rainy season (December-April) with extensive flooding and a dry season (May-November). Within the dry season, there is a cold dry season (May-August) and a hot dry season (September-November). Both wildlife and human activity is centered along the Luangwa River at the boundary of SLNP and adjacent GMAs, particularly during the height of the dry season when water is severely restricted.

We recorded all lion sightings from intensive monitoring of known individuals in 18 prides and 14 male coalitions (hereafter referred to as 'coalitions') from 2008 to 2012, during which all lions were individually-identified using whisker-spot patterns, scarring, and tooth breakage (Pennycuick and Rudnai, 1970; Becker et al., 2013a). Since mid-2009, with permission from the Zambia Department of Veterinary and Livestock Development and ZAWA, we radiocollared one adult female lion in each of eight resident prides and one adult male lion in each of five resident male coalitions, using a combination of VHF and GPS collars. Because lions live in stable social units, VHF radio collars allowed regular resighting of uncollared individuals in our focal study groups, allowing for close monitoring of population size and survival. Data from peripheral, uncollared prides and coalitions sighted opportunistically were used in conjunction with sighting data from the collared resident prides and coalitions, with the presence or absence of a collar considered in statistical analysis. 


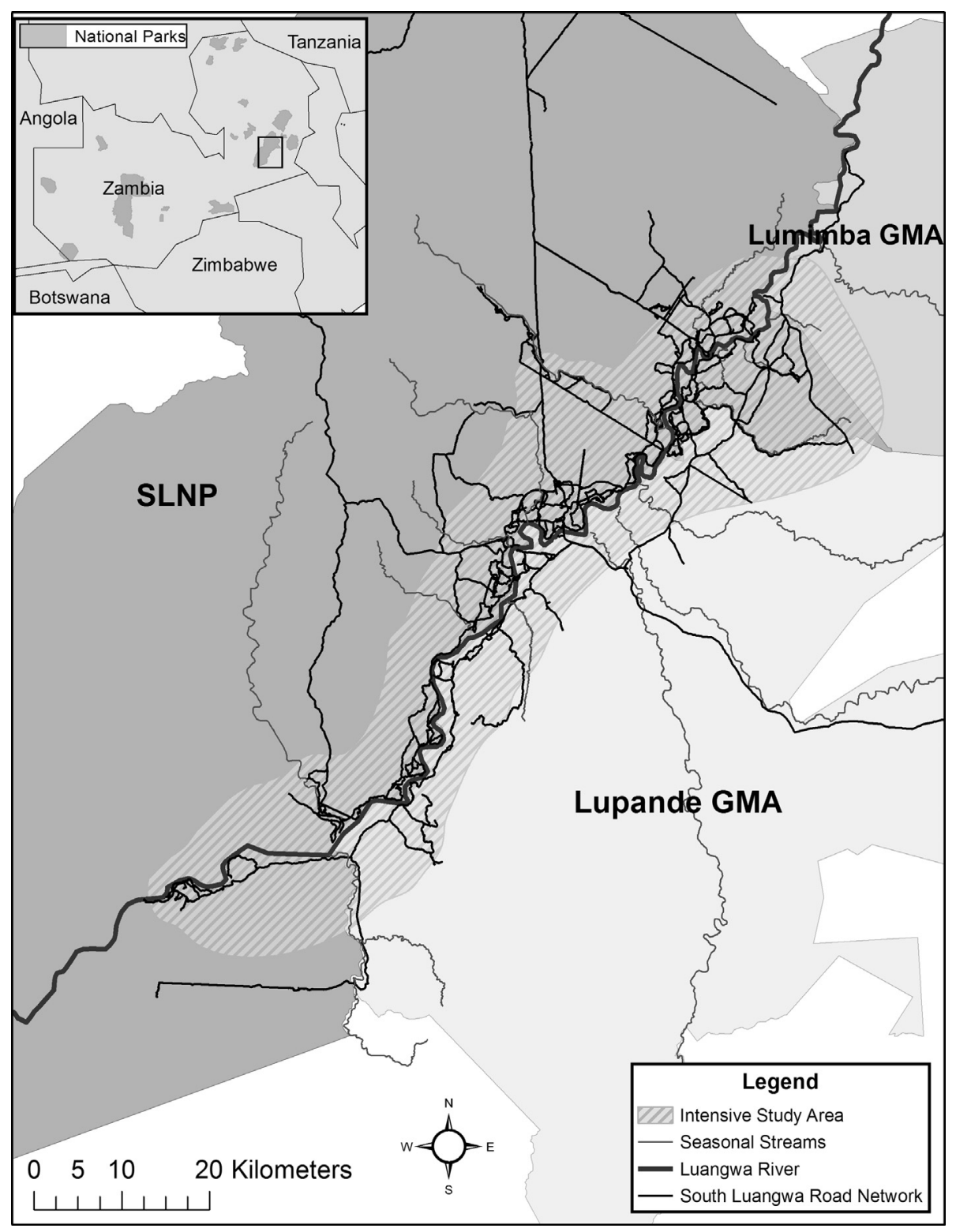

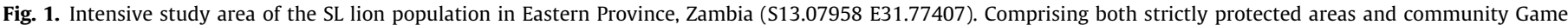
Management Areas the study encompassed the full array of biological and human factors likely to impact Zambian lions.

Field teams worked daily from March to December (>1000 person-days annually), locating individuals using a combination of telemetry and opportunistic sightings. All lions were photographed and compared to identification photos of known individuals. Group affiliation, reproductive status, and fate (alive, dead or not detected) were recorded for each individual at each sighting. Birth dates for individuals first identified as adults were estimated using established standards for nose-pigmentation pattern, tooth wear and coloration, and facial scarring (Whitman et al., 2004; Whitman and Packer, 2007), and by comparison with known-age individuals in this population. We obtained additional data from sightings and photographs by commercial safari guides, clients, and film crews operating in the intensive study area. When possible, causes of mortality were determined via observations, necropsies, and harvest data from hunting concessions. As the identity of a harvested adult male lion could not always be confirmed (see Section 3.1), the disappearance of a known lion was attributed to a harvest when coinciding with the reported harvest of a lion within that known lion's home range. Data used in this study were restricted to the 8-month dry period (April-November) that facilitated intensive monitoring throughout the study area.

\subsection{Estimation of population size, growth rate and density}

We used closed mark-recapture models to estimate population size as the number of lions counted divided by the estimated probability of detection (Otis et al., 1978). For each individual in each of five years (2008-2012), we constructed eight month detection histories recording whether each known lion was detected (1) or not (0) each month. We used Program MARK to fit capture-markrecapture models to these detection histories, estimating the monthly probability of initial detection $(\hat{p})$, subsequent detection $(\hat{c})$, and population size $(\widehat{N})$ (White and Burnham, 1999). Analyzing each year's data separately, we used Akaike's Information Criteria corrected for small sample size (AICc) to evaluate a set of models that allowed $\hat{p}$ and $\hat{c}$ to vary by age, sex, season and location. We used the same model for population estimation in each year, as is desirable for unbiased estimation of population trends 
(Williams et al., 2001). The models' assumption of demographic closure over eight months is reasonable for these data, which were characterized by long inter-birth intervals, reproduction spread across all seasons and relatively low annual natural mortality in most age classes (Packer et al., 1988 , 2001). Support for the assumption of geographic closure is described in Section 4.2.

AICc scores consistently provided the strongest support for Huggins closed-capture models with individual heterogeneity in the likelihood of detection (Huggins, 1989, 1991). Within the Huggins heterogeneity model, the data consistently supported models with variation in detection probability among two seasons (AprilSeptember, and October-November), roughly corresponding to the cold-dry and hot-dry seasons respectively, and in which the probability of initial detection differed from the probability of subsequent detection $(\hat{p} \neq \hat{c})$, probably because decreasing water availability caused prey to concentrate, and thus increased lion detection with the progression of the dry season. In each year, we excluded the detection histories of individuals known to have died during that year, and added these individuals to $\widehat{N}$ from the mark-recapture model to produce a final estimate of population size at the beginning of each year's study period. Because we detected ecologically meaningful differences among annual estimates of population size (with $p<0.05$ ) power analysis was not necessary.

Annual population growth rates $\left(\lambda_{t}\right)$ were estimated as $\left(\widehat{N}_{t+1} / \widehat{N}_{t}\right)$, with $80 \%, 90 \%$, and $95 \%$ confidence intervals estimated by parametric bootstrapping in $\mathrm{R}$ ( $\mathrm{R}$ Core Team 2014) with 10,000 replications, assuming that population sizes were distributed normally with the mean and variance estimated by the mark-recapture model. The population growth rate $(\lambda)$ for the entire period was estimated as the geometric mean of annual growth rates with a confidence intervals estimated using the deltamethod() function in the msm package (Jackson, 2011) of $\mathrm{R}$ (Seber, 1982). We estimated $95 \%, 90 \%$ and $80 \%$ confidence limits to provide retrospective power analysis.

We converted estimates of population size to two estimates of population density. A 'maximum density' with a minimum bound on the area used by these lions was estimated by dividing estimated population size by the area of the 95th percentile isopleth of a kernel utilization distribution (Worton, 1989) fit to all lion locations using Hawth's Tools (Beyer, 2004) in ArcGIS 9.2 (ESRI 2006; Fig. 4). This isopleth (hereafter referred to as utilized area) represented the area unquestionably utilized by the Luangwa Valley lion population. Because this method likely overestimates true density (Sollmann et al., 2012), a 'minimum density' with a maximum bound on the area sampled, equal to the area of our study site $\left(2775 \mathrm{~km}^{2}\right)$ was also estimated. A buffer was not applied to this maximum area because search effort was lower at the periphery of the study site, it is likely that unidentified lions entered the periphery of the study area (particularly from the west) more often than identified lions left it, and several patterns in the data suggest that such movements were not common (see Sections 3 and 4).

\subsection{Estimation of age- and sex-specific survival}

We used a multiple-age Cormac-Jolly-Seber (CJS) model to estimate age- and sex-specific annual apparent survival rates $(\hat{\varphi})$ and annual detection probabilities $(\hat{p})$ for five biologically meaningful age classes: cub ( $0-1$ years old), sub-adult ( $2-3$ years old), sexually-mature young adult (4-5 years old), prime adult (6-7 years old) and old adult ( $8+$ years old). We collapsed the eight-month annual encounter histories described above into two four-month occasions per year, where the detection or nondetection of each individual was recorded for each four month period (July 31st and November 31st) resulting in a 10-occasion encounter history for each individual for the entire 5-year study period. This collapsed encounter history yielded adequate probability of detection for all prides and coalitions in the study area. Given the small number of individuals known to have died (directly observed or identified from a carcass) during the study period (see Section 3.1), these individuals were excluded from this analysis, because including them would require a combination of recovery and recapture models that also estimate a site fidelity parameter for each age and sex class (Burnham, 1993), and separation was observed during model selection without these additional parameters (see below). To control for possible heterogeneity in capture probability and meet the assumptions of CJS models, covariates of survival and detection were included for each individual indicating their sex and whether they were ever part of a radio-collared group (a covariate hereafter referred to as group, with collared groups having a higher detection probability). Age class was assigned to each individual based on its age on July 31 st of the year it was first observed (July 31 st was the first capture occasion of each year). This allowed individuals to be grouped into age-class cohorts and age with subsequent July 31st occasions. We allowed detection probability to vary among age classes, sexes, and group, but assumed constant detection probability for each of these classes across the study period.

We constructed an a priori set of models wherein survival and detection rates varied by age and sex (the effects of primary interest) and by the presence/absence of a radio collar within a pride and the sex of the collared animal (because males and females differ in patterns of association). All models were corrected for extrabinomial variation in survival rates by using $\hat{c}$ (estimated as deviance/df) as a variance inflation factor. We compared models using Akaike's Information Criterion with correction for sample size and extrabinomial variation (QAICc), and used model averaging over all models within 2 QAIC scores from the best-supported model, implemented with the model.avg() function of the $\mathrm{R}$ package MuMIn (Barton, 2013), to account for uncertainty in model selection to produce estimates of unconditional apparent survival (Burnham and Anderson, 1998). When implementing the mode$\operatorname{l.avg()}$ function to estimate standard errors, we used the revised variance estimator of Burnham and Anderson (2004, their Eq. (4)) to improve coverage. Separation occurred in models that estimated $\hat{\varphi}$ and $\hat{p}$ separately for each sex in each age class (indicated by MLE of parameter standard errors), so we limited the final model list to those that pooled the effect of sex across two or more age classes.

The average age at which we first detected cubs was 4.29 months $(\mathrm{SE}=0.32$ ), so we corrected sex-specific $\hat{\varphi}$ and $\hat{p}$ for cubs by exponentiation (exponent $=12 /(12-4.29)=1.56$ ) to yield annualized survival rates. This adjustment assumes that the survival rate in the first 4.29 months of a cub's life is similar to the following 7.71 months of the lion's first year. This assumption will yield over-estimates if cub survival is lower in the first months of life, particularly during turnovers of territorial male coalition and low prey availability (Pusey and Packer, 1987; Packer et al., 1988). We calculated 95\% binomial confidence intervals for cub $\hat{\varphi}$ and $\hat{p}$ using the Wilson method as implemented by the binconf() function of the Hmisc package (Harrell $\mathrm{Jr}, 2014$ ) in R.

\section{Results}

\subsection{Observed group structure, known mortality, and age and sex distribution}

A total of 210 lions were individually identified in the South Luangwa study area (hereafter SL), in 18 prides ranging from 1 to 9 adult females with a mean size of $3.27(95 \% \mathrm{CI}=2.80-3.74)$ and 14 male coalitions ranging from 1 to 4 sub-adult and adult males with a mean size of $1.89(95 \% \mathrm{CI}=1.42-2.36)$. Fifteen of 
these individuals were known to have died from natural and human causes including trophy hunting (5), natural injuries (4), infanticide (3), disease (1), wire snare injuries (1), and unknown causes (1). An additional 8 males likely died from trophy hunting because their last sighting coincided with a lion harvest in the same area. Despite CITES reporting requirements, it was difficult to obtain photographs or tissue samples from hunted lions to confirm their identity; of the 46 males harvested during the study period based on annual harvests reported to ZAWA and to ZCP we received identification data for $11 \%(n=5)$ of the hunted lions during the study period. Estimated age of individuals known/suspected to be harvested ranged from 3.75 to 7.65 years old, with a median age of 4.86 years old (mean age 5.21 years old $(S E=0.31$ )).

The proportion of males reaching the prime and old age classes was consistently small, even following years with relatively large cohorts of sub-adults and young adults (Fig. 2). Old adult males never comprised more than $3 \%$ of the population, and the total of prime and old adult males never exceeded $6 \%$ of the population. The age composition of the female population shifted over the study period, with a large cohort born around 2006 moving through successive age classes and relatively low recruitment thereafter, yielding an increasingly senescent female population (Fig. 2).

\subsection{Population size, density, and trend estimates}

Estimates of the local lion population size (excluding cubs < 1 year old) declined from a maximum of 125 in 2009 (95\% CI: 108-167) to a minimum of 94 lions in 2012 (95\% CI: 92-106) (Table 1, Fig. 3a). The coefficient of variation for annual population estimates ranged from 0.30 to 1.14 (Table 1 ). Locations from GPS collared lions and direct observations in the study area covered an area of $1065 \mathrm{~km}^{2}$ (95\% isopleth from kernel utilization distribution), centered along the Luangwa River, including areas in SLNP and Lumimba and Lupande GMAs (Fig. 4).

Assuming constant study area usage by lions and similar annual field effort throughout the study period, mean maximum population density across the study period was estimated to be 10.4 lions (excluding cubs $<1$ year old) per $100 \mathrm{~km}^{2}$ (95\% CI: 9.4-13.3 lions per $100 \mathrm{~km}^{2}$, Table 1 ). Mean minimum population density was estimated to be 4.0 lions per $100 \mathrm{~km}^{2}$ (95\% CI: $3.6-5.3$ per $100 \mathrm{~km}^{2}$, Table 1). Annual estimates of population growth $(\lambda)$ declined through the study period (Fig. $3 \mathrm{~b}$ ) and by the final year was 0.81 (95\% CI: 0.66-1.05; Fig. 3b). The geometric mean of the annual growth rates suggests a decline of $2 \%$ per year, though the uncertainty of this estimate is large $(\bar{\lambda}=0.98,95 \% \mathrm{CI}: 0.79-$ $1.22)$.

\subsection{Survival rates and detection probabilities}

Age- and sex-specific apparent survival rates $(\hat{\varphi})$ from the best model and from model-averaging of a priori models within 2 QAICC scores of the best model (Table 2) are presented in Fig. 5. These models differed in their parameterization of effects of sex on $\varphi$ and $p$ (top model parameterization presented in Table 3), the presence/absence of at least one radio collar within the pride (radio-collared prides were better monitored), and an interaction between sex and the presence/absence of a radio collar on $p$ (radio-collaring improved the detection of females more than males; Table 2). We found no effect of sex on survival among cubs, but sub-adult males had lower survival than sub-adult females. As individuals entered the adult age classes, males continued to show survival rates $30-35 \%$ below the survival of females in the same age class. The low precision of the adult male survival estimates was largely due to the small numbers of males surviving to these classes (given their high probability of detection). There was no

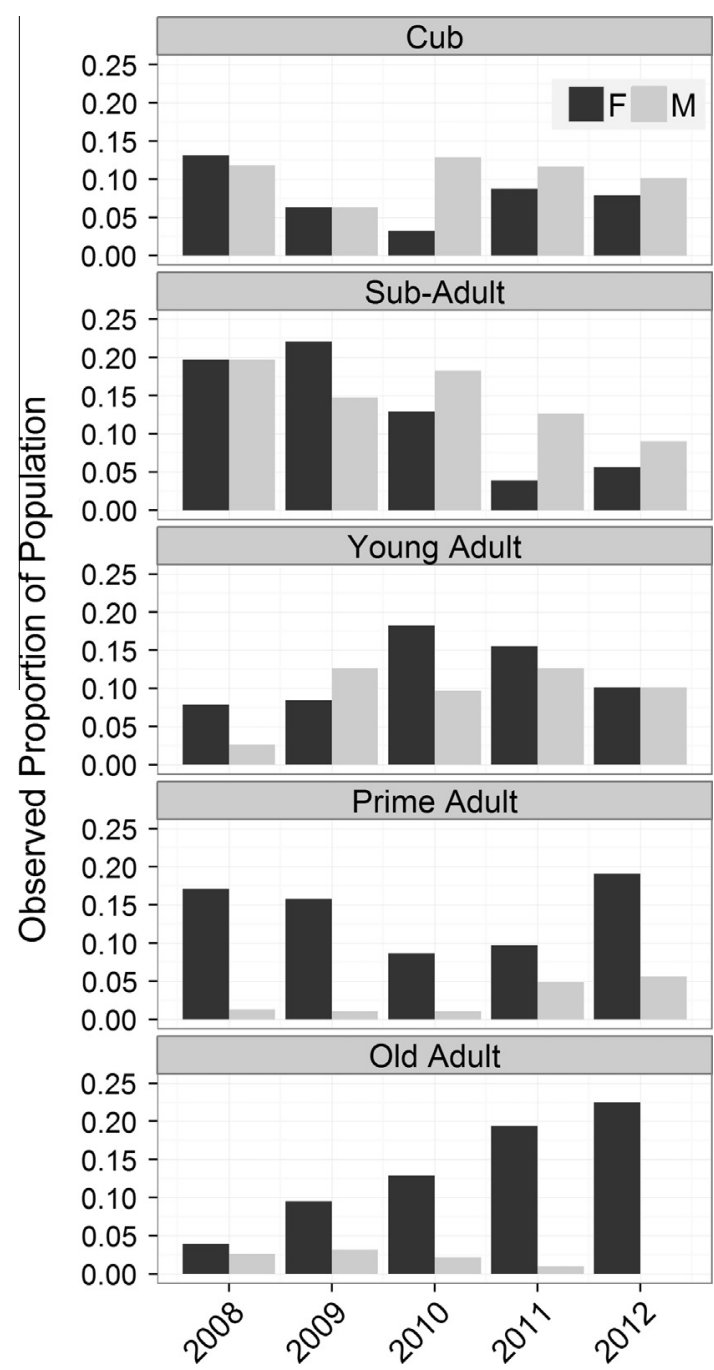

Fig. 2. Observed age and sex distribution for the SL lion population during the study period (2008-2012), indicating a male-depleted (M) and senescing adult female (F) population.

difference in survival between individuals in collared and uncollared groups.

The annual probability of detection $(\hat{p})$ differed between sexes, and was affected by the presence of a radio-collared individual within an individual's group (Fig. 6). Detection did not differ between collared and uncollared groups for males, and increased with age, with male cubs having the lowest $\hat{p}$. The detection of females in the cub and sub-adult age classes was similar for collared and uncollared groups, but was substantially different for collared and uncollared groups in older age classes; adult lionesses in collared groups maintained high $\hat{p}$ (approximately 0.8 ), but $\hat{p}$ was low (approximately 0.2 ) for adult lionesses in uncollared groups.

\section{Discussion}

\subsection{The status of the South Luangwa lion population}

Using five years of intensive monitoring data for a large carnivore population studied with mark-recapture methods, our estimates of maximum density indicate that this portion of Zambia's largest lion population attains local densities comparable to other stronghold lion populations (e.g. Creel and Creel, 1997; Hanby et al., 1995; Smuts, 1976). Relative to previous SL lion density 
Table 1

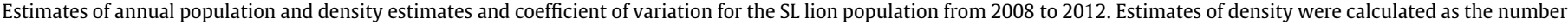

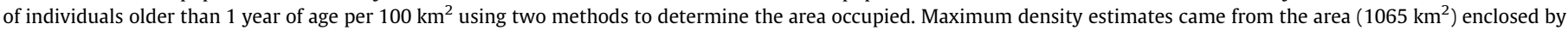
the $95 \%$ isopleth of a kernel utilization distribution fit to known lion locations. Minimum density estimates came from the entire intensive study area ( $\left.2775 \mathrm{~km}^{2}\right)$.

\begin{tabular}{|c|c|c|c|c|c|c|c|c|c|}
\hline Year & $\begin{array}{l}\text { Number of } \\
\text { lions observed }\end{array}$ & $\begin{array}{l}\text { SL lion } \\
\text { population estimate }\end{array}$ & SE & $\begin{array}{l}\text { Coefficient } \\
\text { of variation }\end{array}$ & $95 \% \mathrm{CI}$ & $\begin{array}{l}\text { Maximum } \\
\text { density estimate }\end{array}$ & $\begin{array}{l}95 \% \mathrm{CI} \text { for } \\
\text { maximum density }\end{array}$ & $\begin{array}{l}\text { Minimum } \\
\text { density estimate }\end{array}$ & $\begin{array}{l}\text { 95\% CI for } \\
\text { minimum density }\end{array}$ \\
\hline 2008 & 77 & 102 & 8.08 & 0.70 & $90-123$ & 9.58 & $8.45-11.55$ & 3.67 & $3.24-4.43$ \\
\hline 2009 & 95 & 125 & 14.1 & 1.10 & $108-167$ & 11.74 & $10.14-15.68$ & 4.50 & $3.89-6.82$ \\
\hline 2010 & 99 & 118 & 8.81 & 0.74 & $106-142$ & 11.08 & 9.95-13.33 & 4.25 & $3.82-5.12$ \\
\hline 2011 & 106 & 116 & 12.8 & 1.14 & $106-171$ & 10.89 & 9.95-16.06 & 4.18 & $3.82-6.16$ \\
\hline 2012 & 91 & 94 & 2.93 & 0.30 & $92-106$ & 8.83 & $8.64-9.95$ & 3.38 & $3.31-3.82$ \\
\hline
\end{tabular}
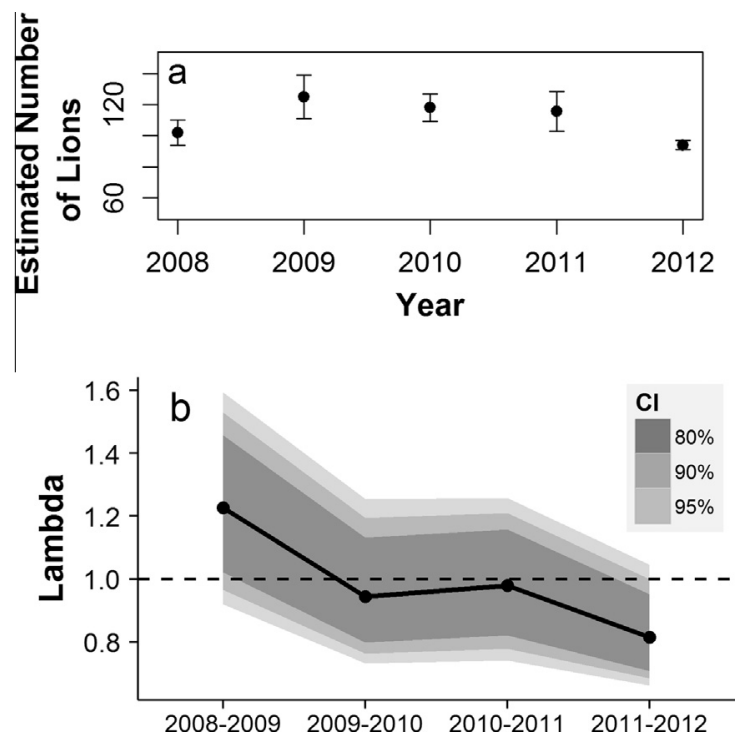

Fig. 3. (a) SL lion population estimates from a Huggins closed capture model with individual heterogeneity in detection probability from 2008 to 2012. (b) Trends in annual population growth rate $(\lambda)$ through time. The dashed line indicates a stable population $(\lambda=1.0)$. Shaded areas indicate $80 \%, 90 \%$, and $95 \%$ confidence intervals (CI) from parametric bootstrapping.

estimates, our maximum density estimate of $8.8-11.7$ lions ( $>1$ year old) focused on the area known to be used by identified lions, while Becker et al. (2013b) reported 3.5 lions (>2 years old) per $100 \mathrm{~km}$ for the same $2775 \mathrm{~km}^{2}$ study area, but including areas that were not know to be used by identified lions, away from the Luangwa River. In the current study, estimates for this larger area yielded densities of 3.7-4.5 lions ( $>1$ year old) per $100 \mathrm{~km}^{2}$. Thus, estimated lion density in other portions of the Luangwa ecosystem is lower than within the focal study area. Even in this stronghold population, estimated lion density at broad spatial scales is considerably lower than has been reported for several other areas.

Our analyses also detected a significant decrease in population size (or density) from 2009 to 2012 and an overall decline of $2 \%$ per year, although no single annual population growth estimate differed from $\lambda=1$ with certainty $>80 \%$. Thus, intensive monitoring provided data sufficiently precise to detect a decline over a period of 5 years with $>95 \%$ confidence. Even for a period of one year, the data were sufficiently precise to provide substantial confidence in the inference that a decline was in progress. In addition, we detected low cub recruitment, low sub-adult and adult male survival, and a senescing female population. Because this study was centered on the core of a stronghold lion population and similar dynamics are likely elsewhere in the country's less robust populations, the reasons for this decline should be addressed to help secure a viable lion populations for the long-term ecological benefits and for Zambia's tourism industry.

\subsection{Drivers in the dynamics of the South Luangwa lion population}

Modeling Zambian lion populations under different harvest management scenarios, Becker et al. (2013b) found age-based harvests coupled with reduced quotas were likely to be sustainable, provided net growth was stable, but more conservative management strategies were necessary where net growth was negative. Our results provide the first statistically rigorous estimates of trends in population size and demography for Zambian lions and indicate a declining population that requires population recovery measures beyond harvest adjustments.

CJS models cannot distinguish between permanent emigration and death, so it might be argued that some male lions were simply not detected or that their disappearance was often due to permanent emigration, and that trophy hunted males were also largely immigrants from outside the study population. However, permanent emigration and potential violations of the closure assumption probably had little effect on the patterns we observed for several reasons. First, detection rates of sub-adult and young adult males, the age classes most likely to disperse, were closely comparable to those of collared sub-adult and adult females, who very rarely disperse (Fig. 6; Schaller, 1972). Second, it was uncommon for unknown lions to immigrate into the intensive study area, while we regularly detected multiple dispersals of subadult and adult males within the study area. Third, the intensive study area was much larger than and included areas peripheral to the utilized area, clearly indicating that the study population rarely used the periphery. Fourth, we documented the disappearance of 46

Table 2

The five best-supported Cormack-Jolly-Seber models of survival, as determined by QAICc scores. All models were required to estimate $\hat{\varphi}$ and $\hat{p}$ for each of the five age classes. The effects of sex on $\varphi$ and $p$, as well as the presence of a collar and an interaction between sex and collar on $p$ were modeled as constant for all adults (adult(.)), two classes of adults (YA = PA, PA = OA) or constant for individual age classes (YA= young adult age class; $\mathrm{PA}=$ prime adult age class; $\mathrm{OA}=$ old adult age class).

\begin{tabular}{llll}
\hline Model & Delta QAICc & QAICc weights & Number of parameters \\
\hline$\phi$ (age \& sex-Adult(.)), $p$ (age, sex-Adult(.), collar-Adult(.), sex*collar-Adult(.)) & 0.00 & 0.33 & 22 \\
$\phi$ (age \& sex-Adult(.)), $p$ (age, sex-Adult(.), collar-Adult(.)) & 1.14 & 0.19 & 19 \\
$\phi$ (age \& sex-Adult(.)), p(age, sex-PA = OA, collar-Adult(.), sex*collar-Adult(.)) & 1.43 & 0.16 & 23 \\
$\phi$ (age \& sex-YA = PA), p(age, sex-PA = OA, collar-Adult(.), sex*collar-Adult(.)) & 2.17 & 0.11 & 23 \\
$\phi$ (age \& sex-YA = PA), p(age, sex-Adult(.), collar-Adult(.) & 3.28 & 0.06 & 20 \\
\hline
\end{tabular}




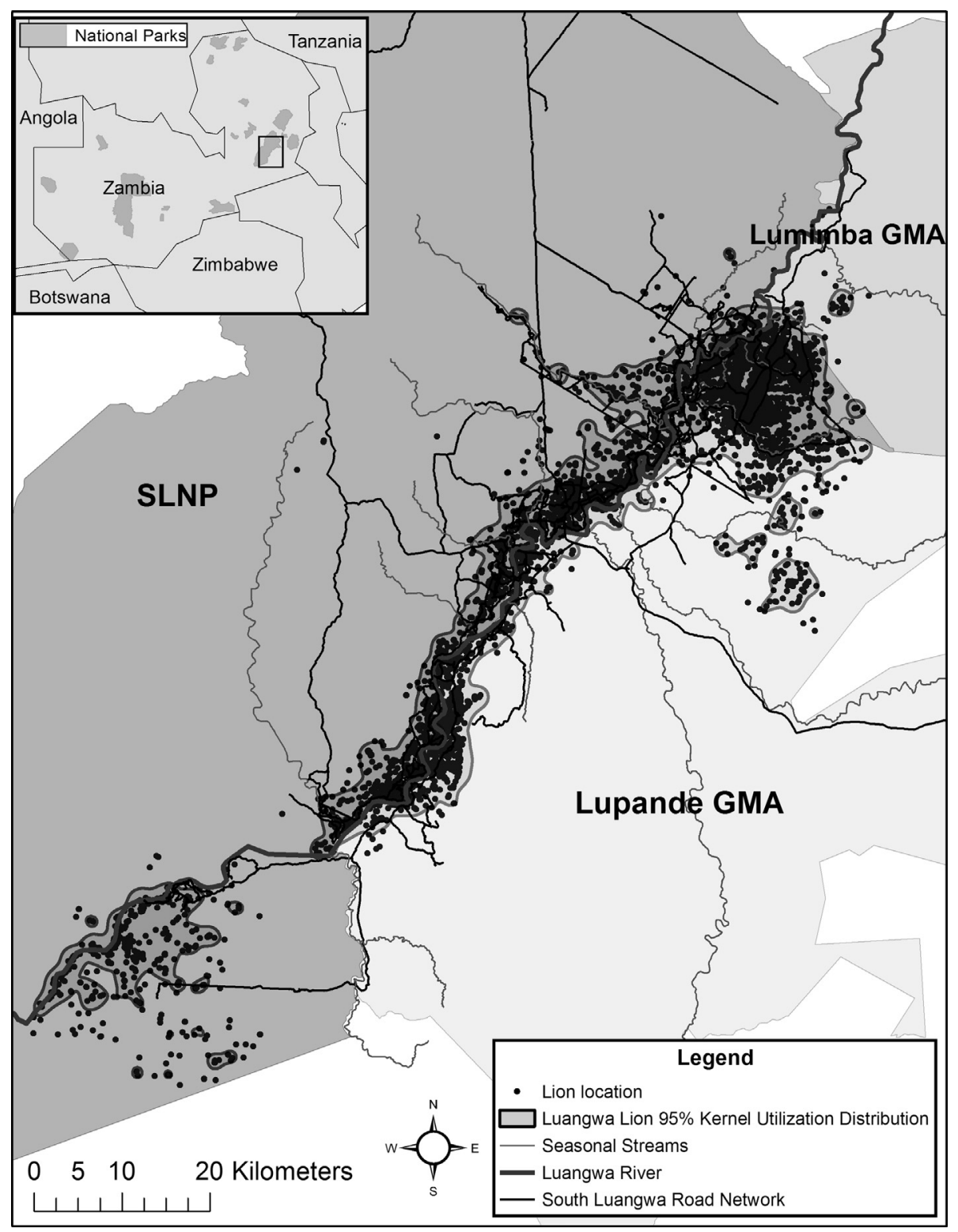

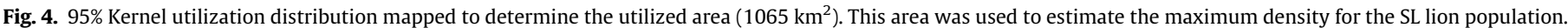

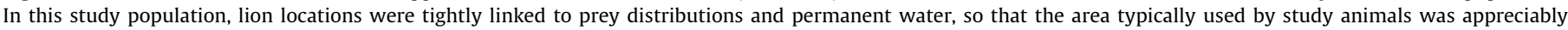
smaller than the intensive study area $\left(2775 \mathrm{~km}^{2}\right.$, see Fig. 1).

males > 3 years old from 2009 to 2012 (excluding 2008 given it was the first study year and could not be calculated), which closely matches the 46 males harvested in the study area from 2008 to 2012. Hunters typically did not provide photographs of harvested lions; however, all lions for which we did obtain pictures were known study animals. Finally, male coalition spatial movements and known fates of male lions indicated that the GMAs acted as an attractive sink for males in the study area, with coalition turnover due to trophy hunting continually creating open territories and weakening established coalitions by removing their members. These vacancies attracted male coalitions from within the population's core via the 'vacuum effect 'described by Loveridge et al. (2007, 2010).

Natural mortality and anthropogenic sources of mortality other than trophy hunting contributed to the patterns we observed. Snaring by-catch would probably have significant impacts on lion dynamics in our study area if not controlled, but the majority ( $n=13$, or $87 \%$ ) of known snared lions on our site were immobilized for snare-removal and successfully treated for injuries during the study period (Becker et al., 2013a). Snaring of target herbivore species is likely to have more serious long-term impacts on the underlying dynamics of this lion population, but the loss of potential prey to wire snares would be detrimental to all age and sex classes and has yet to be quantified. For these reasons, it is unlikely that factors other than trophy hunting significantly contributed to the severe male depletion of the South Luangwa lion population. Additional data on fecundity and cub recruitment are needed to better understand the dynamics of this population but infanticide following turnover in male coalitions is well-documented in lions (Bertram, 1975; Packer and Pusey, 1984; Pusey and Packer, 1994; Packer et al., 2001), and increased turnover of male coalitions from trophy hunting is expected to produce the low cub recruitment that we observed (Whitman et al., 2004).

\subsection{Future management and conservation of Zambian lions}

While overharvesting of lions has been well-documented throughout Africa (Loveridge et al., 2007, 2010; Packer et al., 


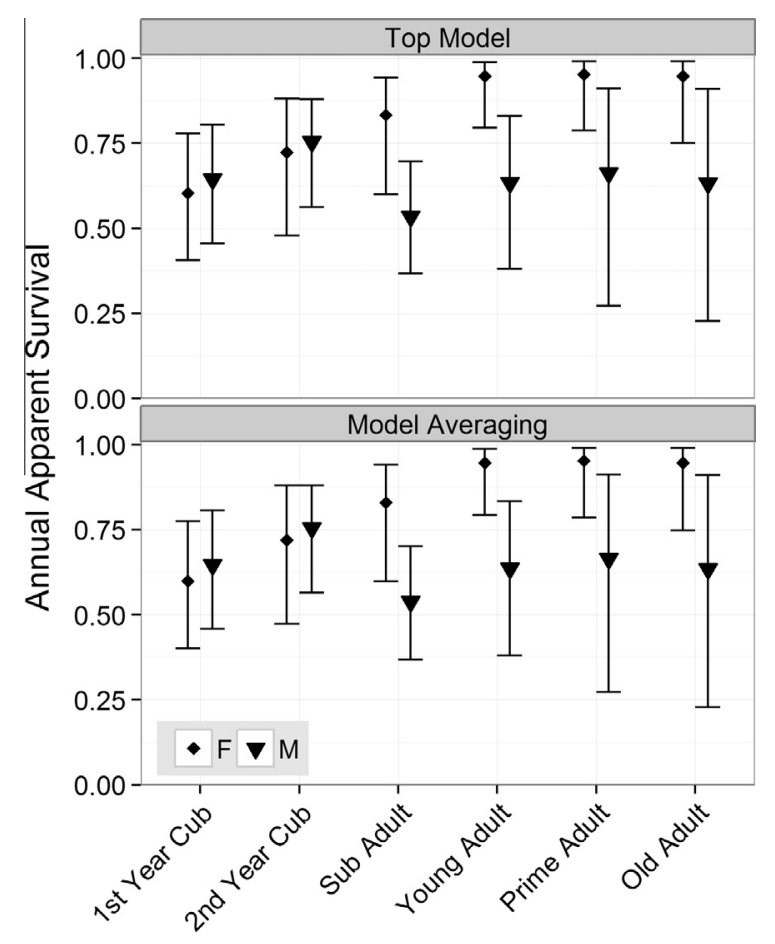

Fig. 5. Annual apparent survival rates $(\hat{\varphi})$ for the SL lion population, estimated by the single best supported Cormack-Jolly-Seber model (upper panel) and by model averaging (lower panel; see Table 2). Error bars indicate 95\% binomial confidence intervals. While male and female annual apparent survival are similar in the early age classes, male annual apparent survival beginning in the sub-adult age classes consistently tended to be lower than apparent survival for females (though not statistically significant given overlapping $95 \%$ confidence intervals).

2009, 2011), a number of practices have been proposed to help ensure that hunting is sustainable, including conservative quotas (0.5 lions $/ 1000 \mathrm{~km}^{2}$; Packer et al., 2011), harvest restricted to older age-classes, changes in the quota allocation structure and accurate, and transparent trophy monitoring and enforcement (Lindsey et al., 2013a). Annual lion harvests in our study area ranged from 1.86 to 2.56 lions $/ 1000 \mathrm{~km}^{2}$, up to five times higher than the
0.5 lions $/ 1000 \mathrm{~km}^{2}$ recommended by Packer et al. (2011), with offtake heavily concentrated along the park boundaries. Not surprisingly, sustained high offtake resulted in a reduction in the age of harvested males, with an increasing number of sub-adult and young adult males shot because few males older than the recommended 6 years (Whitman et al., 2004) remained to fill the allotted quotas. Given the severe male depletion, poor cub recruitment and declining SL population prior to the 2013 ban, we recommend continuation of the lion hunting ban until at least 2016 to help stabilize the female age distribution, improve cub recruitment for both sexes, and restore the adult male age classes. However, lion hunting should only resume with all of the suggested practices described above, with close monitoring to prevent unsustainable harvesting. In addition, given that lion hunting in Zambia his centered mainly in the Kafue and Luangwa ecosystems, rotation of hunting between these two lion populations on a three year cycle could be considered to further ensure that hunting is sustainable. To evaluate the impacts of the hunting ban and other factors on lion demography and dynamics, the intensive monitoring undertaken for this study should be continued, to test whether survival and population dynamics respond as predicted.

While our results suggest a recovery period for lions from trophy hunting is warranted, a serious side-effect of the complete ban on all trophy hunting in Zambia is the loss of wildlife-based tourism throughout $167,000 \mathrm{~km}^{2}$ of lion habitat in the GMAs where these activities occurred and no wildlife-based revenue is now generated. Many of these areas are currently not developed or well-suited for photo-tourism, and are experiencing significant human impacts from land conversion and bushmeat poaching (Watson et al., 2013, 2014). Bushmeat poaching with wire-snares is widespread and increasing in Zambia (Becker et al., 2013b; Lindsey et al., 2013b; Midlane, 2014), and is strongly correlated with human settlement, which is estimated to be increasing at a rate of 18 ha per daylight hour in the Luangwa and Kafue regions (Watson et al., 2013, 2014). Removal of wildlife-based economies in these areas is likely to have severe negative consequences for wildlife populations and habitat and should not be undertaken without careful consideration and implementation of alternatives (Lindsey et al., 2012). Given the difficulties in establishing alternatives, improved management of hunting may be the most effective immediate solution, though options for promoting and expanding

Table 3

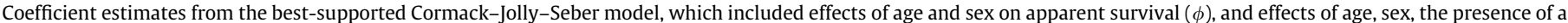
radio-collared animal, and the sex of the collared animal on detection $(p)\{\phi($ age $\&$ sex-Adult(.)), $p$ (age, sex-Adult(.), collar-Adult(.), sex*collar-Adult(.))\}.

\begin{tabular}{|c|c|c|c|c|c|c|}
\hline$\beta$ & Effect of & Parameter affected & Estimate & SE & $95 \% \mathrm{LCI}$ & $95 \% \mathrm{UCI}$ \\
\hline 1 & F cub & $\varphi$ & 0.962815 & 0.535858 & -0.08747 & 2.013096 \\
\hline 2 & F sub-adult & $\varphi$ & 1.61072 & 0.615069 & 0.405185 & 2.816256 \\
\hline 3 & F young adult & $\varphi$ & 2.884205 & 0.776886 & 1.361509 & 4.406901 \\
\hline 4 & F prime adult & $\varphi$ & 3.012064 & 0.864877 & 1.316905 & 4.707223 \\
\hline 5 & F old adult & $\varphi$ & 2.880182 & 0.90587 & 1.104676 & 4.655688 \\
\hline 6 & M cub adjustment & $\varphi$ & 0.159858 & 0.695888 & -1.20408 & 1.523798 \\
\hline 7 & M SA adjustment & $\varphi$ & -1.46767 & 0.706414 & -2.85224 & -0.08309 \\
\hline 8 & $\mathrm{M}$ adult adjustment & $\varphi$ & -2.33482 & 0.781898 & -3.86734 & -0.8023 \\
\hline 9 & F cub & $p$ & 0.429533 & 0.656112 & -0.85645 & 1.715512 \\
\hline 10 & F sub-adult & $p$ & -0.42469 & 0.41533 & -1.23873 & 0.389358 \\
\hline 11 & F young adult & $p$ & -1.3242 & 0.349468 & -2.00916 & -0.63924 \\
\hline 12 & F prime adult & $p$ & -1.38331 & 0.345124 & -2.05975 & -0.70687 \\
\hline 13 & F old adult & $p$ & -1.79636 & 0.34891 & -2.48023 & -1.1125 \\
\hline 14 & M cub adjustment & $p$ & 0.085186 & 0.88182 & -1.64318 & 1.813553 \\
\hline 15 & M SA adjustment & $p$ & 1.534648 & 0.581216 & 0.395464 & 2.673831 \\
\hline 16 & $\mathrm{M}$ adult adjustment & $p$ & 2.671828 & 0.598422 & 1.498922 & 3.844734 \\
\hline 17 & Collar cub adjustment & $p$ & -1.26707 & 0.852558 & -2.93808 & 0.403945 \\
\hline 18 & Collar SA adjustment & $p$ & 1.589845 & 0.614089 & 0.386231 & 2.793459 \\
\hline 19 & Collar adult adjustment & $p$ & 2.818953 & 0.343646 & 2.145408 & 3.492498 \\
\hline 20 & $\mathrm{M} \times$ collar cub adjustment & $p$ & 1.721782 & 1.183512 & -0.5979 & 4.041465 \\
\hline 21 & $\mathrm{M} \times$ collar SA adjustment & $p$ & -0.46639 & 1.377435 & -3.16617 & 2.233378 \\
\hline 22 & $\mathrm{M} \times$ collar adult adjustment & $p$ & -2.59707 & 0.996547 & -4.5503 & -0.64384 \\
\hline
\end{tabular}




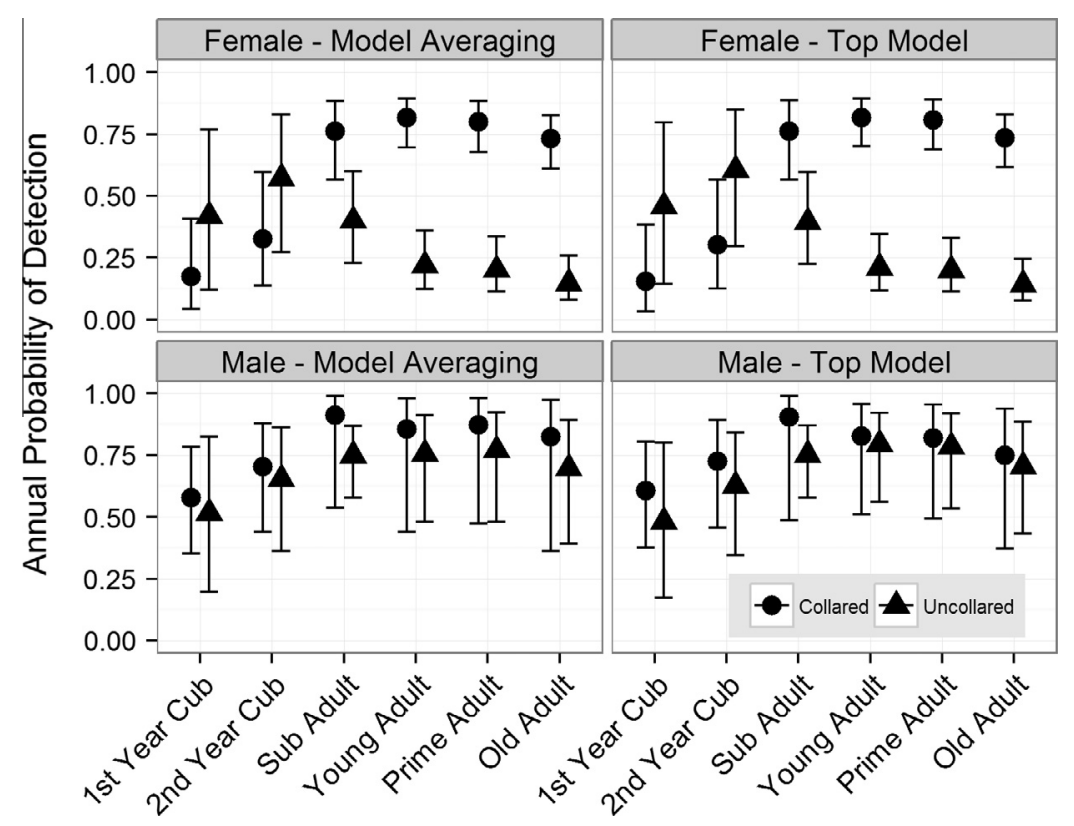

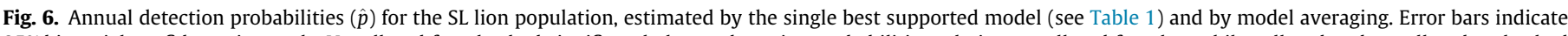

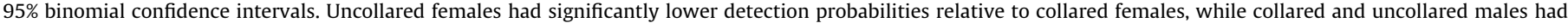
similarly high detection probabilities.

photo-tourism should also be expanded given their economic benefits (Lindsey et al., 2014). While trophy hunting could be sustainable with the suggestion modifications, uncontrolled effects of bushmeat poaching and human encroachment are likely to present much greater threats to the long-term viability of Zambian lions, their prey and their habitats than hunting, unless an array of wildlife-based economies is maintained as widely as possible (Lindsey et al., 2014).

\subsection{The case for intensive monitoring studies}

Even with an intensive monitoring effort spanning five years and requiring high levels of effort, there was appreciable uncertainty around the estimates reported in this study, owing to the difficulties in finding and monitoring low density, wide-ranging, and declining species. This uncertainty, however, was much less than that of other methods commonly used for large carnivores. For example, Midlane (2014) reported coefficients of variation between 2.22 and 0.95 for spoor-count and call-in estimates of lion abundance in northern Kafue National Park. In the year (2012) with the most precise abundance estimate in this study, the coefficient of variation was 0.3 . Thus, intensive monitoring produced estimates with $3 \mathrm{X}$ to $7 \mathrm{X}$ greater precision than rapid indices of abundance. This increased precision is highly valuable when examining population trends or testing the effectiveness of management actions.

These differences in uncertainty and the need for evaluation of the underlying causes of carnivore declines both highlight the importance of intensive, long-term monitoring efforts and the need for closely linking them with larger-scale IOA methods to obtain a more thorough understanding of large carnivore dynamics. Indices of abundance are valuable over large spatial scales and when budgets, resources, and time are limited, or when very little is known about a large carnivore population in a given area. These conditions pertain to many large carnivore populations. Nonetheless, the most common research and monitoring objective for any carnivore conservation project is to determine population size, trends and the causes of these trends. To meet these objectives will require monitoring programs that effectively mesh IOA and intensive monitoring.

\subsection{Conclusions}

As global large carnivore declines accelerate, precise estimates of population sizes and trends are critical to efficiently detect population declines, to determine their causes, and to implement corrective management and conservation measures. While rapid and economical survey methods based on indices of abundance are an important conservation tool, they rarely provide the necessary precision to inform and guide management policies, and they rarely provide information about the factors causing an observed decline. Intensive long-term monitoring to detect and address declines should be implemented wherever possible for remaining stronghold populations of large carnivores. A high priority for large carnivore conservation and management should be to effectively combine both indices of abundance and intensive monitoring approaches to provide precise data over large scales.

\section{Acknowledgements}

We thank the Zambia Wildlife Authority and the Zambia Department of Veterinary and Livestock Development for permission and collaboration with this research. This work was funded through grants by the Worldwide Fund for Nature-Netherlands, National Science Foundation Animal Behavior Program under IOS-1145749, Painted Dog Conservation Inc., Mfuwe Lodge/Bushcamp Company, National Geographic's Big Cats Initiative, and Seaworld and Busch Gardens Fund. Thanks to all ZAWA staff members, safari guides and managers, professional hunters, and visitors too numerous to name who contributed to the monitoring efforts reported in this manuscript. Special thanks to A. Banda, G. Banda, H. Banda, P. Bouley, C. Chirwa, C. Harrison, D. Hafey, A. Makakula, R. McRobb, F. Otten, A. Rosenblatt, and E. Sadowski for their assistance with data collection. Thanks to J. Rotella for assistance with the analysis of survival rates.

\section{References}

Astle, W.L., 1988. Republic of Zambia, South Luangwa National Park Map, Landscape and Vegetation. Lovell Johns, Oxford. 
Astle, W.L., Webster, R., Lawrance, C.J., 1969. Land classification for management planning in the Luangwa Valley of Zambia. J. Appl. Ecol. 6, 143-169.

Balme, G.A., Hunter, L.T.B., Slotow, R., 2009. Evaluating methods for counting cryptic carnivores. J. Wildlife Manage. 73, 433-441.

Barton, K., 2013. MuMIn: Multi-model inference. R package version 1.9.13 <http:/ CRAN.R-project.org/package=MuMIn>.

Bauer, H., Nowell, K., Packer, C., 2013. Panthera leo. In: IUCN 2013. IUCN Red List of Threatened Species. Version 2013.1. <www.iucnredlist.org>

Bauer, D., Schiess-Meier, M., Mill, D.R., Gusset, M., 2014. Using spoor and prey counts to determine temporal and spatial variation in lion (Panthera leo) density. Can. J. Zool. 92, 97-104.

Becker, M., McRobb, R., Watson, F., Droge, E., Kanyembo, B., Murdoch, J., Kakumbi, C., 2013a. Evaluating wire-snare poaching trends and the impacts of by-catch on elephants and large carnivores. Biol. Conserv. 158, 26-36.

Becker, M.S., Watson, F.G.R., Droge, E., Leigh, K., Carlson, R., Carlson, A.A., 2013b. Estimating past and future male loss in three Zambian lion populations. J. Wildlife Manage. 77, 128-142.

Berentsen, A.R., Dunbar, M.R., Becker, M.S., M’soka, J., Droge, E., Sakuya, N., Matandiko, W., McRobb, R., Mulipukwa, C., Hanlon, C.A., 2013. Rabies, canine distemper and canine parvovirus exposure in large carnivore communities from two Zambian ecosystems. Vector-Borne Zoonotic Dis. 13, 643-649.

Bertram, B.C.R., 1975. Social factors influencing reproduction in wild lions. J. Zool. $177,463-482$.

Beyer, H.L., 2004. Hawth's Analysis Tools for ArcGIS <http://www.spatialecology. com/htools>.

Brashares, J.S., Arcese, P., Sam, M.K., 2001. Human demography and reserve size predict wildlife extinction in West Africa. Proc. R. Soc. B Biol. Sci. 268, 2473 2478.

Brink, H., Smith, R.J., Skinner, K., 2012. Methods for lion monitoring: a comparison from the Selous game reserve, Tanzania. Afr. J. Ecol., 1-10.

Burnham, K.P., 1993. A theory for combined analysis of ring recovery and recapture data. In: Lebreton, J.D., North, P.M. (Eds.), Marked Individuals in the Study of Bird Population. Birkhäuser-Verlag, Basel.

Burnham, K.P., Anderson, D., 1998. Model Selection and Inference: A Practica Information-Theoretic Approach. Springer-Verlag, New York, New York, USA.

Burnham, K.P., Anderson, D.R., 2004. Multimodel inference understanding AIC and BIC in model selection. Sociol. Method Res. 33, 261-304.

Cardillo, M., Purvis, A., Sechrest, W., Gittleman, J.L., Bielby, J., Mace, G.M., 2004 Human population density and extinction risk in the world's carnivores. PLoS Biol. 2. http://dx.doi.org/10.1371/journal.pbio.0020197.t003.

Chomba, C., Mwenya, A.N., Nyirenda, N., 2011. Wildlife legislation and institutiona reforms in Zambia for the period 1912-2011. J. Sustain. Dev. Afr. 13, 218-236.

Conroy, M.J., 1996. Abundance indices. In: Wilson, D.E., Cole, F.R., Nichols, J.D. Rudran, R., Foster, S.M. (Eds.), Measuring and Monitoring Biological Diversity: Standard Methods for Mammals. Smithsonian Institution Press, Washington, pp. 179-192.

Cozzi, G., Broekhuis, F., McNutt, J.W Schmid, B., 2013. Density and habitat use of lions and spotted hyenas in northern Botswana and the influence of survey and ecological variables on call-in survey estimation. Biodivers. Conserv. 22, 2937 2956.

Creel, S., Becker, M.S., Durant, S.M., M'Soka, J., Matandiko, W., Dickman, A.J. Christianson, D., Dröge, E., Mweetwa, T., Pettorelli, N., Rosenblatt, E., Schuette P., Woodroffe, R., Bashir, S., Beudels-Jamar, R.C., Blake, S., Borner, M. Breitenmoser, C., Broekhuis, F., Cozzi, G., Davenport, T.R.B., Deutsch, J., Dollar, L., Dolrenry, S., Douglas-Hamilton, I., Fitzherbert, E., Foley, C., Hazzah, L., Henschel, P., Hilborn, R., Hopcraft, J.G.C., Ikanda, D., Jacobson, A., Joubert, B., Joubert, D., Kelly, M.S., Lichtenfeld, L., Mace, G.M., Milanzi, J., Mitchell, N. Msuha, M., Muir, R., Nyahongo, J., Pimm, S., Purchase, G., Schenck, C., SilleroZubiri, C., Sinclair, A.R.E., Songorwa, A.N., Stanley-Price, M., Tehou, J.A., Trout, C., Wall, J., Wittemyer, G., Zimmermann, A., 2013. Conserving large populations of lions - the argument for fences has holes. Ecol. Lett. 16, 1413-e3.

Creel, S., Creel, N.M., 1997. Lion density and population structure in the Selous game reserve: evaluation of hunting quotas and offtake. Afr. J. Ecol. 35, 83-93.

Creel, S., Rosenblatt, E., 2013. Using pedigree reconstruction to estimate population size: genotypes are more than individually unique marks. Ecol. Evol. 3, 12941304.

Creel, S., Spong, G., Sands, J.L., Rotella, J., Zeigle, J., Joe, L., Smith, D., 2003. Population size estimation in Yellowstone wolves with error-prone noninvasive microsatellite genotypes. Mol. Ecol. 12, 2003-2009.

Dudley, N. (Ed.), 2008. Guidelines for Applying Protected Area Management Categories. IUCN, Gland, Switzerland, p. 86.

Durant, S.M., Bashir, S., Maddox, T.M., Laurenson, M.K., 2007. Relating long-term studies to conservation practice: the case of the Serengeti Cheetah Project. Conserv. Biol. 21, 602-611.

Durant, S.M., Craft, M.E., Hilborn, R., Bashir, S., Hando, J., Thomas, L., 2011. Longterm trends in carnivore abundance using distance sampling in Serenget National Park, Tanzania. J. Appl. Ecol. 48, 1490-1500.

ESRI 2006. ArcGIS Desktop: Release 9.2. Redlands, CA.

Estes, J.A. Terborgh, J. Brashares, J.S., Power, M.E. Berger, J., Bond, W.J. Carpenter, S.R., Essington, T.E., Holt, R.D., Jackson, J.B.C., Marquis, R.J., Oksanen, L., Oksanen, T., Paine, R.T., Pikitch, E.K., Ripple, W.J., Sandin, S.A., Scheffer, M., Schoener, T.W. Shurin, J.B., Sinclair, R.E., Soule, M.E., Virtanen, R., Wardless, D.A., 2011. Trophic downgrading of planet earth. Science 333, 301-306.

Ferreira, S.M., Funston, P.J., 2010. Estimating lion population variables: prey and disease effects in Kruger National Park, South Africa. Wildlife Res. 37, 194 206.
Ferreira, S.M., Govender, D., Herbst, M., 2013. Conservation implications of Kalahari lion population dynamics. Afr. J. Ecol. 51, 176-179.

Funston, P.J., Frank, L.G., Stephens, T., Davidson, Z., Loveridge, A.J., Macdonald, D.W., Durant, S.M., 2010. Substrate and species constraints on the use of track incidences to estimate African large carnivore abundance. J. Zool. 281, 56-65.

Groom, R.J., Funston, P.J., Mandisodza, R., 2014. Surveys of lions Panthera leo in protected areas in Zimbabwe yield disturbing results: what is driving the population collapse? Oryx, 1-9.

Hanby, J.P., Bygott, J.D., Packer, C., 1995. Ecology, demography and behavior of lions in two contrasting habitats: Ngorongoro Crater and the Serengeti Plains. In: Sinclair, A.R.E., Arcese, P. (Eds.), Serengeti II: Dynamics, Management, and Conservation of an Ecosystem. University of Chicago Press, Chicago, pp. 315331.

Harrell Jr, F.E., 2014. Hmisc: Harrell Miscellaneous. R package version 3.14-0 <http://CRAN.R-project.org/package=Hmisc>.

Houser, A.M., Somers, M.J., Boast, L.K., 2009. Spoor density as a measure of true density of a known population of free-ranging wild cheetah in Botswana. J. Zool. $278,108-115$.

Huggins, R.M., 1989. On the statistical analysis of capture experiments. Biometrika 76, $133-140$.

Huggins, R.M., 1991. Some practical aspects of a conditional likelihood approach to capture experiments. Biometrics, 725-732.

Jackson, C.H., 2011. Multi-state models for panel data: the MSM package for R. J. Stat. Software 38, 1-29 <http://www.jstatsoft.org/v38/i08>.

Jackson, R.M., Roe, J.D., Wangchuk, R., Hunter, D.O., 2006. Estimating snow leopard population abundance using photography and capture-recapture techniques. Wildlife Soc. Bul, 34, 772-781.

Karanth, K.U., Gopalaswamy, A.M., Kumar, N.S., Vaidyanathan, S., Nichols, J.D., Mackenzie, D.I., 2011. Monitoring carnivore populations at the landscape scale: occupancy modelling of tigers from sign surveys. J. Appl. Ecol. 48, 1048-1056.

Karanth, K.U., Nichols, J.D., 1998. Estimation of tiger densities in India using photographic captures and recaptures. Ecology 79, 2852-2862.

Karanth, K.U., Nichols, J.D., Kumar, N.S., Link, W.A., Hines, J.E., Orians, G.H., 2004 Tigers and their prey: predicting carnivore densities from prey abundance. Proc. Nat. Acad. Sci. 101, 4854-4858.

Kelly, M.J., Durant, S.M., 2000. Viability of the Serengeti Cheetah. Conserv. Biol. 14, 786-797.

Kiffner, C., Waltert, M., Meyer, B., Muhlenberg, M., 2008. Response of lions (Panthera leo) and spotted hyaenas (Crocuta crocuta) to sound playbacks. Afr. J. Ecol. 46, $223-226$.

Kiffner, C., Meyer, B., Muhlenberg, M., Waltert, M., 2009. Plenty of prey, few predators: what limits lions Panthera leo in Katavi National Park, western Tanzania? Oryx 43, 52-59.

Kohn, M.H., York, E.C., Kamradt, D.A., Haught, G., Sauvajot, R.M., Wayne, R.K., 1999. Estimating population size by genotyping faeces. Proc. R. Soc. London Ser. B 266, 657-663.

Lindsey, P.A., Balme, G.A., Booth, V.R., Midlane, N., 2012. The significance of African lions for the financial viability of trophy hunting and the maintenance of wild land. PLoS One 7 (1), e29332.

Lindsey, P.A., Balme, G., Funston, P., Henschel, P., Hunter, L., Madzikanda, H., Midlane, N., Nyirenda, V., 2013a. The trophy hunting of African lions: scale, current management practices and factors undermining sustainability. Plos One 8, e73808.

Lindsey, P.A., Balme, G., Becker, M., Begg, C., Bento, C., Bocchino, C., Dickman, A. Diggle, R.W., Eves, H., Henschel, P., Lewis, D., Marnewick, K., Mattheus, J., McNutt, J.W., McRobb, R., Midlane, N., Milanzi, J., Morley, R., Murphree, M., Opyene, V., Phadima, J., Purchase, G., Rentsch, D., Roche, C., Shaw, J., Van der Westhuizen, H., Van Vliet, N., Zisadza-Gandiwa, P., 2013b. The bushmeat trade in African savannas: impacts, drivers, and possible solutions. Biol. Conserv. 160, 80-96.

Lindsey, P., Nyirenda, V., Barnes, J., Becker, M.S., McRobb, R., Tambling, C., Taylor, A. Watson, F., T'Sas-Rolfes, M., 2014. Underperformance of African protected area networks and the case for new conservation models: insights from Zambia. PLoS one 9, e94109.

Loveridge, A.J., Hemson, G., Davidson, Z, Macdonald, D.W. 2010. African lions on the edge: reserve boundaries as 'attractive sinks'. In: Macdonald, D.W., Loveridge, A.J. (Eds.), Biology and Conservation of Wild Felids. Oxford University Press, Oxford, United Kingdom, pp. 283-304.

Loveridge, A.J., Searle, A.W., Murindagomo, F., Macdonald, D.W., 2007. The impact of sport-hunting on the population dynamics of an African lion population in a protected area. Biol. Conserv. 134, 548-558.

Mfula, C., 2013. Zambia bans hunting of endangered lions, leopards. Reuters, 10.01.13 <www.reuters.com/article/2013/01/10/uk-zambia-hunting-banidUSLNE90900T20130110 >

Midlane, N., 2014. The conservation status and dynamics of a protected African lion Panthera leo population in Kafue National Park, Zambia. Ph. D. Dissertation. University of Cape Town, South Africa.

Midlane, N., O’Riain, M.J., Balme, G.A., Robinson, H.S., Hunter, L.T.B., 2014. On tracks: a spoor-based occupancy survey of lion (Panthera leo) distribution in Kafue National Park, Zambia. Biol. Conserv. 172, 101-108.

Mills, M.G.L., Juritz, J.M., Zucchini, W., 2001. Estimating the size of spotted hyaena (Crocuta crocuta) populations through playback recordings allowing for nonresponse. Anim. Conserv. 4, 335-343.

Mondol, S., Karanth, K.U., Kumar, N.S., Gopalaswamy, A.M., Andheria, A., Ramakrishnan, U., 2009. Evaluation of non-invasive genetic sampling methods for estimating tiger population size. Biol. Conserv. 142, 2350-2360. 
Ogada, M.O., Woodroffe, R., Oguge, N.O., Frank, L.G., 2003. Limiting depredation by African carnivores: the role of livestock husbandry. Conserv. Biol. 17, 15211530.

Ogutu, J.O., Dublin, H.T., 1998. The response of lions and spotted hyaenas to sound playbacks as a technique for estimating population size. Afr. J. Ecol. 36, 83-95.

Otis, D.L., Burnham, K.P., White, G.C., Anderson, D.R., 1978. Statistical inference from capture data on closed animal populations. Wildlife Monogr., 3-135.

Packer, C., Brink, H., Kissui, B.M., Maliti, H., Kushnir, H., Caro, T., 2011. Effects of trophy hunting on lion and leopard populations in Tanzania. Conserv. Biol. 25, $142-153$.

Packer, C., Herbst, L., Pusey, A.E., Bygott, J.D., Hanby, J.P., Cairns, S.J., Borgerhoff Mulder, M., 1988. Reproductive success of lions. In: Clutton-Brock, T.H. (Ed.), Reproductive Success. University of Chicago Press, Illinois, USA, pp. 363-383.

Packer, C., Kosmala, M., Cooley, H.S., Brink, H., Pintea, L., Garshelis, D., Purchase, G., Strauss, M., Swanson, A., Balme, G., Hunter, L., Nowell, K., 2009. Sport hunting, predator control and conservation of large carnivores. PLoS One 4, e5941.

Packer, C., Pusey, A.E., 1984. Infanticide in carnivores. In: Hausfater, G., Hrdy, S.B. (Eds.), Infanticide in Animals and Man: Comparative and Evolutionary Perspectives. Aldine, New York, New York, USA, pp. 31-42.

Packer, C., Pusey, A.E., Eberly, A.E., 2001. Egalitarianism in female African lions. Science 22001, 690-693.

Packer, C., Tatar, M., Collins, A., 1998. Reproductive cessation in female mammals. Nature 392, 807-811.

Pennycuick, C.J., Rudnai, J., 1970. A method of identifying individual lions Panthera leo with an analysis of the reliability of identification. J. Zool. (London) 160, 497-508.

Peterson, R.O., 1999. Wolf-moose interaction on Isle Royale: the end of natural regulation? Ecol. Appl. 9, 10-16.

Pusey, A.E., Packer, C., 1987. The evolution of sex-biased dispersal in lions. Behaviour, 275-310.

Pusey, A.E., Packer, C., 1994. Non-offspring nursing in social carnivores: minimizing the costs. Behav. Ecol. 5, 362-374.

Riggio, J., Jacobson, A., Dollar, L., Bauer, H., Becker, M., Dickman, A., Funston, P., Groom, R., Henschel, P., De Iongh, H., Lichtenfeld, L., Pimm, S., 2012. The size of savannah Africa: a lion's (Panthera leo) view. Biodivers. Conserv. 22, 17-35.

Ripple, W.J., Estes, J.A., Beschta, R.L., Wilmers, C.C., Ritchie, E.G., Hebblewhite, M., Berger, J., Elmhagen, B., Letnic, M., Nelson, M.P., Schmitz, O.J., Smith, D.W., Wallach, A.D., Wirsing, A.J., 2014. Status and ecological effects of the world's largest carnivores. Science 343, 151-162.

Schaller, G.B., 1972. The Serengeti Lion: A Study of Predator-Prey Relations. University of Chicago Press, Illinois, USA.

Schuette, P., Wagner, A.P., Wagner, M.E., Creel, S., 2013. Occupancy patterns and niche partitioning within a diverse carnivore community exposed to anthropogenic pressures. Biol. Conserv. 158, 301-312.

Seber, G.A.F., 1982. The Estimation of Animal Abundance and Related Parameters, 2nd ed. Chapman, London and Macmillan, New York.
Smith, D., Ralls, K., Davenport, B., Adams, B., Maldonado, J.E., 2001. Canine assistants for conservationists. Science 291, 435.

Smuts, G.L., 1976. Population characteristics and recent history of lions in two parts of the Kruger National Park. Koedoe 19, 153-164.

Sollmann, R., Gardner, B., Belant, J.L., 2012. How does spatial study design influence density estimates from spatial capture-recapture models? PLoS One 7, e34575.

Stander, P.E., 1998. Spoor counts as indices of large carnivore populations: the relationship between spoor frequency, sampling effort and true density. J. Appl. Ecol. 35, 378-385.

Van Dyke, F.G., Brocke, R.H., Shaw, H.G., 1986. Use of road track counts as indices of mountain lion presence. J. Wildlife Manage. 50, 102-109.

Vitousek, P.M., Mooney, H.A., Lubchenco, J., Melillo, J.M., 1997. Human domination of earth's ecosystems. Science 277, 494-499.

Watson, F., Becker, M.S., McRobb, R., Kanyembo, B., 2013. Spatial patterns of wiresnare poaching: Implications for community conservation in buffer zones around National Parks. Biol. Conserv. 168, 1-9.

Watson, F., Becker, M.S., Milanzi, J., Nyirenda, M., 2014. Assessing human encroachment trends in protected area networks using land use change data: implications for large carnivore conservation. Reg. Environ. Change, 1-15.

White, F., 1983. The Vegetation of Africa: A Descriptive Memoir to Accompany the Unesco/AETFAT/UNSO Vegetation Map of Africa. United Nations Educational, Scientific and Cultural Organization, Paris.

White, G.C., Burnham, K.P., 1999. Program MARK: survival estimation from populations of marked animals. Bird Study 46, 120-139.

Whitman, K.L., 2006. Modelling, monitoring and the sustainable use of lion populations in Tanzania. Ph.D. thesis, University of Minnesota, Twin Cities, Minnesota.

Whitman, K.L., Packer, C., 2007. A Hunter's Guide to Aging Lions in Eastern and Southern Africa. Safari Press, Long Beach.

Whitman, K.L., Starfield, A.M., Quadling, H.S., Packer, C., 2004. Sustainable trophy hunting of African lions. Nature 428, 175-178.

Williams, B.K., Nichols, J.D., Conroy, M.J., 2001. Analysis and Management of Animal Populations. Academic Press, San Diego, p. 817.

Woodroffe, R., 2000. Predators and people: using human densities to interpret declines of large carnivores. Anim. Conserv. 3, 165-173.

Woodroffe, R., Ginsberg, J.R., 1998. Edge effects and the extinction of populations inside protected areas. Science 80, 2126-2128.

Worton, B.J., 1989. Kernel methods for estimating the utilization distribution in home-range studies. Ecology 70, 164-168.

Yamazaki, K., 1996. Social variation of lions in a male-depopulated area in Zambia. J. Wildlife Manage. 60, 490-497.

Zambia Wildlife Authority (ZAWA), 2009. National Conservation Action Plan for cheetahs and wild dog in Zambia. Zambia Wildlife Authority, Chilanga, Zambia.

Zambia Wildlife Authority (ZAWA), 2010. Conservation Action Plan for the Lion in Zambia. Zambia Wildlife Authority, Chilanga, Zambia. 